\title{
Comparative home range size and habitat selection in provisioned and non-provisioned long-tailed macaques (Macaca fascicularis) in Baluran National Park, East Java, Indonesia
}

\author{
Malene F. Hansen \\ Affiliations during research: Research and Conservation, Copenhagen Zoo, Roskildevej 38, \\ 2000 Frederiksberg, Denmark \\ Behavioral Ecology Group, Department of Biology, University of Copenhagen, Univer- \\ sitetsparken 15, building 3, $4^{\text {th }}$ floor, 2100 Copenhagen $\emptyset$, Denmark \\ Current affiliation: Department of Social Sciences, Oxford Brookes University, Oxford, UK \\ malenefriishansen@gmail.com
}

Signe Ellegaard

Behavioral Ecology Group, Department of Biology, University of Copenhagen, Universitetsparken 15, building $3,4^{\text {th }}$ floor, 2100 Copenhagen $\emptyset$, Denmark

Maria M. Moeller

Behavioral Ecology Group, Department of Biology, University of Copenhagen, Universitetsparken 15, building 3, $4^{\text {th }}$ floor, 2100 Copenhagen $\emptyset$, Denmark

Floris M. van Beest

Department of Bioscience, Aarhus University, Frederiksborgsvej 399, 4000 Roskilde, Denmark

Agustin Fuentes

Department of Anthropology, University of Notre Dame, 296 Corbett Family Hall, Notre Dame, IN 46556, USA

Ventie A. Nawangsari

Research and Conservation, Copenhagen Zoo, Roskildevej 38, 2000 Frederiksberg, Denmark Carsten Groendahl

Research and Conservation, Copenhagen Zoo, Roskildevej 38, 2000 Frederiksberg, Denmark Monica L. Frederiksen

Vet Consult, Skovvej 58, 2920 Charlottenlund, Denmark

Mikkel Stelvig

Research and Conservation, Copenhagen Zoo, Roskildevej 38, 2000 Frederiksberg, Denmark 


\title{
Niels M. Schmidt
}

Department of Bioscience, Aarhus University, Frederiksborgsvej 399, 400o Roskilde, Denmark

Carl Traeholt

Research and Conservation, Copenhagen Zoo, Roskildevej 38, 2000 Frederiksberg, Denmark

\section{Torben Dabelsteen}

Behavioral Ecology Group, Department of Biology, University of Copenhagen, Universitetsparken 15, building $3,4^{\text {th }}$ floor, 2100 Copenhagen $\emptyset$, Denmark

\begin{abstract}
The effect of food provisioning on ranging patterns of long-tailed macaques (Macaca fascicularis) in nonanthropogenic areas is largely unknown, as most published studies have focused on urban macaques. In this study, we quantified habitat selection, daily path length and home range size in long-tailed macaques in Baluran National Park, East Java, Indonesia, comparing a non-provisioned to a provisioned group. To track the groups, we deployed six GPS-collars on females in both groups, of which only two collected data. Home range size (90\% Auto-correlated Kernel Density Estimate) was 23 times smaller for the provisioned group (10.62 ha) than the non-provisioned group (249.90 ha). Home range size and area changed from dry to wet season for the non-provisioned group. Provisioned group home range size correlated negatively with number of visitors in the national park. Daily path length was significantly higher for the nonprovisioned group. The provisioned group preferred settlements, where most of the provisioning occurred, and avoided areas with invasive acacia (Acacia nilotica). The non-provisioned group also avoided invasive acacia, preferred secondary forest in the dry season and restored savannah in the wet season. Food provisioning can affect macaque spatial ecology, by shaping daily travel length and home range size, and changing patterns of habitat selection. Even tourism in a managed national park, where provisioning is strictly prohibited although not always enforced, has significant consequences for animal behaviour and their natural ecosystems.
\end{abstract}

\section{Keywords}

behavioural flexibility - conservation - ranging patterns - visitors - wildlife management

\section{Introduction}

The intentional provisioning of food to wildlife by humans occurs globally and is typically done for recreational or management purposes. Indeed, managers can provide food to wildlife populations to improve reproductive output and stimulate population growth
(Milner et al., 2014), or to attract wildlife away from specific areas (Kubasiewicz et al., 2016). The general public also feeds wildlife, which is sometimes perceived as an easy way to interact with wildlife, or to connect with nature (Reynolds et al., 2017). While feeding wildlife can in some cases lead to the desired positive effects on wildlife populations, the 
practice also often promotes negative ecological effects (reviewed in e.g., Milner et al., 2014; Sorensen et al., 2014). For example, it can lead to altered habitat use and shifts in activity within the home range (Cooper et al., 2006), it may lead to changes in the natural foraging behavior of individuals (e.g., begging for food from humans; Samuels \& Beijder, 2004) and it can increase the potential for pathogen spread between wildlife species and possibly to and from humans (Sorensen et al., 2014).

Similarly, provisioning of primates, and long-tailed macaques specifically, may not benefit the species itself, the people or the ecosystems that they inhabit. Although feeding of primates by humans is common across cultures and countries, it has been shown to induce behavioural changes, particularly increases in aggression (e.g., long-tailed macaques, Macaca fascicularis, in Singapore, Yeo \& Neo, 2010) and enhanced risk of road traffic fatalities (Hanuman langurs, Semnopitheaus entellis, in India, Chhangani, 2004). In macaques, provisioning can affect home range size (table 1). Moreover, studies show that provisioned long-tailed macaques typically focus their space use to edges of human influenced habitats (Gumert et al., 2011; Hansen et al., 2019), which may have negative consequences on the ecosystem through reduced seed dispersal (Sha \& Hanya, 2013). In addition, provisioning often facilitates population expansions and larger group sizes in longtailed macaques (Brotcorne, 2014; Brotcorne et al., 2011; Fuentes et al., 2011).

Long-tailed macaques (Macaca fascicularis) are widespread across Southeast Asia and present in South Asia, where they occur

TABLE 1 Home ranges (HA) and core areas (CA) of provisioned and non-provisioned groups of different species of macaques

\begin{tabular}{|c|c|c|c|c|}
\hline Species & Study area & Method & $\begin{array}{l}\text { HA/CA undisturbed/ } \\
\text { non-provisioned (ha) }\end{array}$ & $\begin{array}{l}\text { HA/CA disturbed/ } \\
\text { provisioned (ha) }\end{array}$ \\
\hline $\begin{array}{l}\text { Northern pig- } \\
\text { tailed macaque } \\
{\text { (Macaca leonina })^{*}}^{\text {Maca }}\end{array}$ & $\begin{array}{l}\text { Khao Yai National } \\
\text { Park, Thailand }\end{array}$ & $\begin{array}{l}\text { CHP (characteristic } \\
\text { hull polygons) }\end{array}$ & $306.8 / 115.5$ & $56.3 / 40.1$ \\
\hline $\begin{array}{l}\text { Japanese macaque } \\
(\text { Macaca fuscata })^{* *}\end{array}$ & $\begin{array}{l}\text { Northern Japan Alps, } \\
\text { Kita-azumi and } \\
\text { Minami-azumi } \\
\text { districts of Nagano } \\
\text { Prefecture, Japan }\end{array}$ & $\begin{array}{l}\text { AKDE (adaptive } \\
\text { kernel density } \\
\text { estimation) }\end{array}$ & 460 & 280 \\
\hline $\begin{array}{l}\text { Bonnet macaque } \\
(\text { Macaca radiata })^{* * *}\end{array}$ & $\begin{array}{l}\text { Bandipur National } \\
\text { Park, India }\end{array}$ & - & $25.01-36.49$ & $179.95^{-236.06}$ \\
\hline $\begin{array}{l}\text { Long-tailed } \\
\text { macaque (Macaca } \\
\text { fascicularis) }{ }^{* * * *}\end{array}$ & $\begin{array}{l}\text { Bali Barat National } \\
\text { Park and Ubud Monkey } \\
\text { Forest, Bali, Indonesia }\end{array}$ & $\begin{array}{l}\text { FKDE (fixed kernel } \\
\text { density estimation) }\end{array}$ & $32.5 / 7.72$ & $8.7 / 1.97$ \\
\hline $\begin{array}{l}\text { Tonkean macaque } \\
\text { (Macaca } \\
\text { tonkeana })^{* * * * *}\end{array}$ & $\begin{array}{l}\text { Lore Lindu National } \\
\text { Park, Central Sulawesi, } \\
\text { Indonesia }\end{array}$ & - & 142.75 & 66.75 \\
\hline
\end{tabular}

*(José-Domínguez et al., 2015); **(Izumiyama et al., 2003); ***(Chatterjee et al., 2009; Sinha \& Mukhopadhyay, 2013); ****(Brotcorne, 2014); *****(Riley, 2005). 
in various habitats with different degrees of anthropogenic influence (Ong \& Richardson, 2008). Their opportunistic nature enables them to inhabit most ecosystems across their range (Fooden, 1995; Muroyama \& Eudey, 2004; Fuentes et al., 2008; Gumert, Fuentes \& Jones-Engel, 2011). As anthropogenic impacts on natural habitats have increased, so has the long-tailed macaque's ability to exploit them, which has earned them inappropriate labels such as "weed species" (Richard et al., 1989).

The behaviour of synanthropic long-tailed macaques has received much scientific attention, with an emphasis on the interactions with and impacts of humans (i.e., Fuentes et al., 2007, 2008; Brotcorne et al., 2014, 2017). Ranging patterns and habitat use receive much less attention and findings have been inconsistent. For example, a study in Singapore comparing two neighbouring provisioned groups found that a higher level of provisioning increased home range size (Sha \& Hanya, 2013), while another study comparing provisioned individuals of two different species of macaques (M. fascicularis in Singapore and M. sylvanus in Gibraltar) showed the opposite (Klegarth et al., 2017). These contrasting results suggest that differences in anthropogenic food sources (direct feeding vs refuse sites, and aggregated vs scattered distribution) may have a bigger effect than food quantity on the ranging of provisioned groups. Neither of these studies, however, included a non-provisioned group.

Home range sizes of long-tailed macaques vary greatly, yet in general, non-provisioned groups tend to have larger home ranges than provisioned groups (Fooden, 1995). In studies of provisioned urban long-tailed macaques in Singapore, home range sizes ranged from 9.5 ha - 88.8 ha (Sha \& Hanya, 2013; Klegarth et al., 2017). Home ranges for non-provisioned long-tailed macaque groups across Southeast Asia inhabiting mangrove or lowland forest ranged from 12.5 ha to <30o ha. Large home range sizes (>100 ha) were found in both mangrove and secondary forest (Fooden, 1995).

Studies of non-provisioned long-tailed macaque ranging patterns are few and most research dates back to 1995 (Foodens compilation) and 1983, where primatologists researched ranging patterns, group composition and social behaviour in non-provisioned long-tailed macaques in Sumatra (van Schaik et al., 1983). Knowledge on the ranging behaviour of non-provisioned long-tailed macaques can increase our understanding of provisioning on ranging patterns and habitat use in provisioned groups, and enable us to compare non-provisioned and provisioned groups. This could be especially valuable if they inhabit the same area. Here we quantify home range sizes, daily travel length, and habitat selection patterns of both non-provisioned and provisioned groups of long-tailed macaques inhabiting Baluran National Park, East Java, Indonesia. This area is ideal for this study, as provisioned and non-provisioned groups occur in close proximity and occupy the same habitats. We expect to find a smaller home range of the provisioned group compared to the non-provisioned group based on our preliminary observations as well as the information compiled by Fooden (1995), with a difference in habitat selection between the two groups, with the provisioned group preferring sites, where provisioning occurs. We also expect to find a seasonal variation in ranging patterns of both groups.

\section{Methods}

\section{Ethics statement}

Research complied with animal care and animal handling protocols of Copenhagen Zoo, under senior veterinarian Carsten Groendahl, who also attended GPS collaring of all females together with senior veterinarian Monica Loenborg Frederiksen from Vet Consult. We 
have complied with ethics guidelines from University of Copenhagen Good Research and Publication Practice, the Indonesian Ministry of Research (RISTEK), and Baluran National Park management.

\section{Study site}

Baluran National Park ( $7^{\circ} 50^{\prime} 0^{\prime \prime}$ S, $\left.114^{\circ} 22^{\prime} 0^{\prime \prime} E\right)$ is located on the most northeastern part of East Java, Indonesia at the Bali strait. East Java experiences a high human abundance (40 mill.) (EB, 2018), which has severely affected wildlife, that has either become extirpated (Jackson \& Nowell, 2008), reduced to small populations in small protected enclaves (Fernando et al., 2006), or partially adapted to the anthropogenic influence and increased the human-wildlife co-occurrence surface (Fooden, 1995). Baluran National Park, like East Java as a whole, experiences considerable human influence. A busy regional road runs through the national park on the southwestern side and tourists visit the park daily. A large settlement on the northern border uses national park land for agriculture and domestic cattle grazing, and the local community relies on the park for extraction of fruits, medicinal plants and grass for domestic cattle (Hansen et al., 2015; Pudyatmoko, 2017; Pudyatmoko et al., 2018). The park also includes a large teak (Tectona grandis) plantation on the Western side. Commuters and tourists provision long-tailed macaques along roads and in tourist areas. They feed long-tailed macaques directly by either throwing or giving the macaques human foods. Long-tailed macaques also raid crops and trash bins and steal from humans. We never observed provisioning of other wildlife species.

\section{Data collection}

We collected data from one provisioned and one non-provisioned study group. The nonprovisioned group consisted of mean $\pm S D$ (sample size 4):61 \pm 11 individuals, divided into
$3 \pm 1$ infants $(0-1 \mathrm{y}), 20 \pm 5$ juveniles $(1-4 \mathrm{y}), 5 \pm 1$ subadult males $(4-6 \mathrm{y}), 15 \pm 5$ females $(>3.5 \mathrm{y})$, and $5 \pm 1$ adult males $(>6 \mathrm{y}$ ) (age and sex classes from van Schaik et al., 1983; Brotcorne, 2014). We used the guide developed by Brotcorne (2014) to assess sex/age group by physical characteristics. The non-provisioned group inhabited an area adjacent to the tourist areas of the park, which included invasive acacia (Acacia nilotica), secondary forest, savannah and a savannah restoration site with ongoing Acacia nilotica eradication, which in our analysis is termed "restored savannah". Because of large flight distance of the group, and general vigilant behaviour, we followed this group for approximately one month pre-deployment to determine that this group did not interact with humans, nor feed on anthropogenic foods. We were also able to assess the daily ranging pattern, and sleeping trees of the group.

The provisioned group consisted of mean \pm SD (sample size 7 ): $89 \pm 15.5$ individuals; $11 \pm 6$ infants $(0-1 y), 40 \pm 3$ juveniles $(1-4 y), 11 \pm 2$ subadult males (4-6 y), 26 \pm 1 females ( $>3.5 \mathrm{y}$ ), $4 \pm 1$ males $(>6 \mathrm{y})$, and inhabited the highly visited tourist area of Bama beach adjacent to and occasionally occurring in the same areas as the non-provisioned group. This group relied on anthropogenic foods through direct and indirect provisioning when visitors were present (Hansen, pers. obs. 2015-2018). On days with few visitors, and early morning (before $10 \mathrm{am}$ ) and late afternoon (after $4 \mathrm{pm}$ ), the group foraged outside Bama beach. Bama beach is a beach located at a seafront enclosed by mangrove on either sides.

To analyse ranging patterns we GPScollared adult female individuals in both groups because long-tailed macaques live in multi-male multi-female groups with male dispersal and female philopatry (Thierry, 2007). We wanted to ensure the collared individual remained in the group. We caught adult females (only catching individuals that had 


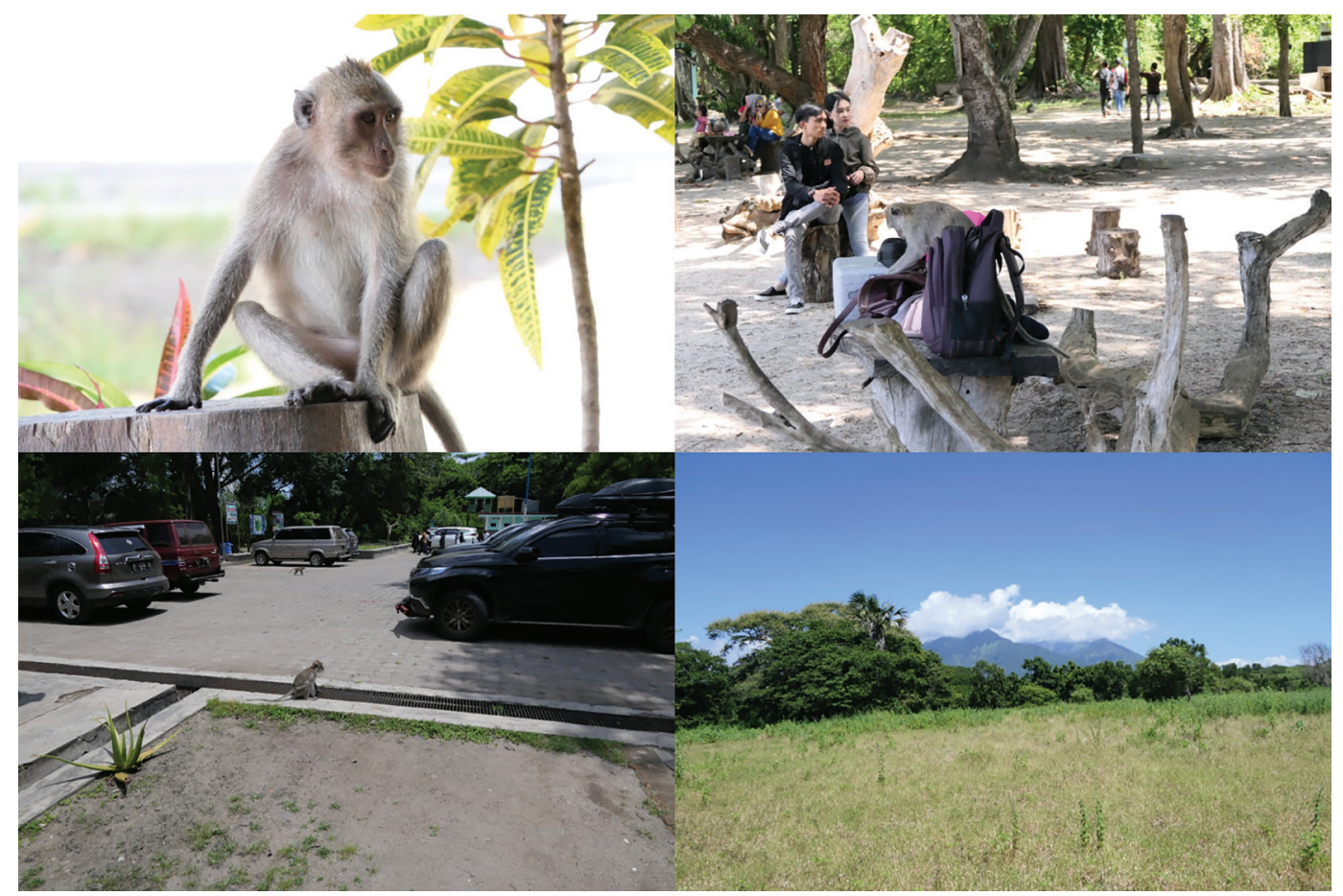

FIGURE 1 Above left: Juvenile long-tailed macaque (Macaca fascicularis) from the provisioned group at Bama beach. Above right: One of the collared females in the provisioned group at Bama beach searching through backpacks after her collar had been remotely released. Her collar was the one that collected data for the provisioned group. Below left: Bama beach parking lot with two long-tailed macaques among the vehicles. Below right: Habitat of the non-provisioned group with restored savannah, native acacia trees (Acacia leucophloea) and mount Baluran in the background. All photos are from Baluran National Park, east Java, Indonesia by Malene Friis Hansen.

previously given birth assessed by nipple shape and size) to ensure the individuals would not grow extensively while wearing the collar. Groups are generally very cohesive, and travel together (van Schaik \& van Noordwijk, 1988).

We collected data using Followit Tellus Micro collars without iridium or GSM transfer. Tellus Micro collars (from here on GPScollars) are too small ( $77 \mathrm{~g}$ ) to contain iridium and there is no GSM coverage within Baluran National Park. Therefore, we used a VHF receiver to locate the collars, and a UHF receiver to connect with the collar, download data, and drop-off the collars. Before deployment we conducted stationary and non-stationary tests of GPS collars to test their functionality (Klegarth, 2017).
We programmed the GPS collars to obtain fixes every 45 minutes from 0400-1815 hours to save battery life, and under the assumption that the long-tailed macaques would remain in their sleeping tree from $1815^{-0400}$ hours according to our initial observations and the observations of Baluran National Park staff. We created the fix schedule together with Followit technicians to ensure battery life for at least 6 months. Battery life was much lower than anticipated however, and the rainy season began earlier than usual. This left us with data from the following months: 9 September - 12 November 2017 (determined as dry season in this study, as there was no rain) and 13 November 2017 - 11 January 2018 (defined as wet season in this study, because 
it rained almost every day beginning 13 November 2017).

To assess if the collared females were representative of their groups, and remained in their groups two-three observers followed both groups for 14 days (8 hours/day), conducting scan sampling on the group and focal animal sampling on the collared female at the same time using the same behaviour categories (Altmann, 1974).

Baluran National Park management provided exact visitor number for each day during our study period for us to compare with the ranging pattern of the provisioned group. All visitors entering Baluran National Park ended up at Bama beach. They usually arrived between 10 am and $4 \mathrm{pm}$.

\section{GPS collar deployment}

Initial deployment included six GPS-collars on different deployment dates from September 2017 - November 2017, two GPS-collars in the non-provisioned group, and four GPS-collars in the provisioned group. Four GPS-collars did not function, although we experienced successful pre-deployment tests (Klegarth, 2017), and therefore only two GPScollars collected data, one in each group. GPS-collar functionality was low, and so was remote drop-off abilities. We strongly recommend rigorous testing of small size collars before deployment in difficult assessable freeranging animals (Dore et al., 2020). GPS-collars must weigh below $5 \%$ of the animal body weight (Sikes, 2016), our GPS-collar:animal weight mean was $1.57 \% \pm 0.25$.

For all deployments at least two veterinarians trained in GPS-collaring of wildlife were present, as well as individuals trained in handling long-tailed macaques. We caught the provisioned females in a catching cage, and the non-provisioned females in their sleeping trees by surrounding them at dusk and darting them with a Dan Inject JM Special $\mathrm{CO}_{2}$ powered dart gun in the trees. We climbed the trees to retrieve them.

We sedated the females with a mixture containing ketamine, midazolam, tiletamine+ zolazepam $\left(\right.$ Zoletil $\left.^{\circ}\right)$, and medetomidine $(7 \mathrm{mg}$, $0.7 \mathrm{mg}, 3.5+3.5 \mathrm{mg}$ and $0.175 \mathrm{mg}$ respectively in $0,4 \mathrm{ml}$ volume). The females received a mixture of $0.08 \mathrm{ml} / \mathrm{kg}(0.4 \mathrm{ml}$ total dose) on average by intramuscular (IM) injection, allowing us to safely fit the collars around their neck. Anaesthesia of the macaques varied from 30 minutes to 60 minutes. Monitoring during anaesthesia consisted of pulse oximetry, non-invasive blood pressure, heart and respiratory rate and rectal temperature. We continuously supplied oxygen by facemask $(2 \mathrm{~L} /$ minute). We followed the guidelines of GPS-collar fitting as outlined by Klegarth (2017). After administering an antisedation $0.75 \mathrm{mg}$ atipamezole $(0.15 \mathrm{ml}$ Antise$\operatorname{dan}^{\circ}$ ) intramuscularly, and meloxicam for pain modulation and long acting antibiotics to prevent infection in the dart wound, we released them back with their group, and monitored them for the following week to assess their welfare.

Collar data collection periods were 79 days (1 October 2017 - 18 December 2017) for the non-provisioned group, which is 43 days dry season and 36 days wet season, and 59 days ( 14 November 2017 - 11 January 2018) for the provisioned group all wet season.

\section{Data analyses}

We used the behavioural observations to assess if the females were representative of their group. Employing a binomial test, the behaviour of the focal individuals were compared to the behaviour of the group to determine if the females performed the same behaviour as the majority of the group more than would be expected by chance.

We excluded data collected the first 24 hours after fitting the GPS collars from any 
analysis to remove potential capture (nonnormal) behaviour as much as possible.

We checked for outliers i.e. impossible movements in our location data (defined as movements of $>15 \mathrm{~km} / \mathrm{h}$ within 15 minute consecutive positions), but found none. Therefore, we used the full dataset in our analyses (except sleeping positions and the first day locations). For sleeping positions, we included locations with a Horizontal Dilution of Precision $($ HDOP $)<4$.

All statistical analysis was conducted in R 3.4.3 (R Core Team, 2017).

\section{Daily path length and speed}

We calculated the Euclidian distance (m) between successive relocations (i.e. the step length) using the package adehabitatLT (Calenge, 2011). We then calculated the sum of the step lengths for each day and defined these as the daily path length (DPL). We tested for differences in DPL between groups within seasons using a t-test as data were normally distributed. To investigate variation in travel speeds when moving through different habitats, we divided step lengths according to the habitat in which the last position of that step length calculation was taken (i.e., the habitat, the individual was moving towards). We used a non-parametric Mann-Whitney U-test to test for differences between speeds in habitats within groups and between seasons, where data were normally distributed.

\section{Home range}

For home range and core area assessments we employed the CTMM R package (Fleming et al., 2019). The non-parametric Autocorrelated Kernel Density Estimate (AKDE) analysis is the most effective home range estimator for auto-correlated tracking data (Fleming \& Calabrese, 2017). The AKDE analysis provides low, mean and high estimates of home ranges according to the chosen isopleths from the provided GPS locations. We used the 90\% isopleth to determine home range (the area in which the macaques range) and 50\% isopleth to determine core area (the area the macaques use the most within the home range). We estimated the percentage cover of habitats inside home ranges through mapping in QGIS.

We used the AKDE 90\% home range estimate to identify home range of the provisioned group according to visitor number. We divided visitor number into four categories: $<100$ (weekdays in non-holiday season, 14 days in total (November 2017)), 100-300 (weekends in non-holiday season and weekdays in holiday season, 27 days in total (December 2018 - January 2019)), 301-500 (weekends in holiday season, 6 days in total), >500 (holidays, 12 days in total). We pooled the GPS positions into four categories according to the visitor number categories. Because of the disparity in number of days within each visitor category, we ran the analysis with other categories (i.e., <100, 100-200, 201-300, 301-400, 401-500, $>500$ ), yet still experienced home range to decrease with increasing visitor number as presented below. The chosen categories reflected the temporal change in visitor numbers best.

\section{Habitat selection}

For habitat selection analysis we used the amt $\mathrm{R}$ package, and several supporting packages such as lubridate and raster (Signer et al., 2019b). Amt uses integrated Step-Selection Functions (iSSF). Habitat selection and movement processes are allowed for simultaneously in iSSF (Avgar et al., 2017), which simulates animal space use through a random walk model (Signer et al., 2019a). The amt package uses a normal approximation Wald test to analyse any significant statistical difference in selection between habitat types (Signer et al., 2019a). Running GPS positions from one animal at a time, we first created a track and then investigated sampling rate and chose the 
temporal resolution of successive steps (here $45 \mathrm{~min}$ ) from which to resample our steps. We included time of day (night-time 1730 hours o70o hours) in our analysis. We then incorporated one raster containing all habitat covariates and then chose a single habitat raster covariate at a time to run against the all habitat raster. We chose to extract covariates from the end of each step. Extracting the covariate from the end of a step provides information on habitat selection, whereas extracting it at the beginning provides animal movement process information (Signer et al., 2019a). Fitting von Mises distribution to turning angles and a gamma distribution to step lengths we created and paired nine random steps to the observed steps. We then fitted a logistic regression model with time of day included, and used Akaike Information Criterion (AIC) for model selection. Significant results show either a preference or avoidance for that particular habitat over all other habitats (Avgar et al., 2017; Signer et al., 2019a; Signer et al., 2019b). The model included habitats with sufficient successive steps with a $45 \mathrm{~min}$ temporal resolution in the logistic regression model (table $5 \mathrm{a}$ and $4 \mathrm{~b}$ ). We ran all habitats for both groups. The macaques did not use the habitats not included.

\section{Maps}

We created maps in QGIS 2.18 using polygons from AKDE analysis, sleeping positions and habitat ESRI shapefiles provided by Baluran National Park, amended with contemporary updates according to Google Earth. We converted the ESRI shapefiles to raster layers in R and employed them for all analysis where appropriate.

\section{Results}

Simultaneous scan sampling and focal animal sampling results for both groups showed a significant correlation between the activity of the collared female and the group (Binomial test, $P=0.0046$ and $P<0.0001$ for the non-provisioned and the provisioned groups respectively). The similar activity budgets supports our initial assumption that the collared females were representative of their respective groups in their activity budget.

The mean fix success rate for both collars was low; $65.9 \% \pm 4.24$, which means that $\sim 65 \%$ of position fix attempts were successful. However, locations were generally of high quality with a mean $3 \mathrm{D}$ fix success rate of $93.3 \% \pm 0.2$, and a mean horizontal dilution of precision of $1.8 \pm \mathbf{1 . 6}$.

Mean daily path length was $1387 \pm 506 \mathrm{~m}$ for the provisioned group and $3236 \pm 968 \mathrm{~m}$ for the non-provisioned group in the same season. This was significantly lower $(T=10.46, \mathrm{df}=46$, $P<0.005)$ for the provisioned group and less than half that of the non-provisioned group.

Estimated mean $90 \%$ home range of the non-provisioned group was app. 23 times larger than that of the provisioned group (table 2, fig. 2). Home ranges of both groups covered various habitats (table 3 ). Home ranges did not overlap in our analysis, yet we did observe the non-provisioned group to use an area inside the home range of the provisioned group after this study.

Sleeping areas of the provisioned group clustered to the north of the home range (fig. 2).

There was a negative correlation between daylight home range size and number of visitors in the provisioned group (Spearman rank correlation, $\mathrm{RHO}=-0.97, P<0.005)$, with decreasing home range size with increasing visitor densities (table 4, fig. 3). The smallest of the home ranges (visitor number $>500$ ) was focused around the settlements and recreational areas in the tourist area Bama. When visitor number decreased, home range increased to include more habitats (table 4, fig. 3). 
TABLE 2 Autocorrelated density estimate (AKDE) home ranges, core areas and densities with lowest and highest estimate of home ranges and core areas

\begin{tabular}{llcrrrr}
\hline Group & Season & Isopleth* & Low (ha) & Mean (ha) & High (ha) & $\begin{array}{c}\text { Density } \\
\text { (ind/ha) }\end{array}$ \\
\hline Provisioned & Wet & 90 & 9.71 & 10.62 & 11.57 & 8.38 \\
Non-provisioned & Wet & 90 & 206.92 & 249.40 & 295.78 & 0.25 \\
Provisioned & Wet & 50 & 2.20 & 2.41 & 2.62 & \\
Non-provisioned & Wet & $5^{0}$ & 54.79 & 66.03 & 78.31 & \\
Non-provisioned & Dry & 90 & 299.02 & 365.08 & 437.64 & 0.17 \\
Non-provisioned & Dry & $5^{0}$ & 94.25 & 115.07 & 137.94 & \\
\hline
\end{tabular}

*The contour lines that here contain 90 or $50 \%$ of all the GPS locations.

TABLE 3 Habitat percentage cover in the 9o\% Autocorrelated Kernel Density Estimate home ranges of both groups in wet season*

\begin{tabular}{llc}
\hline Habitat & Group & Percentage cover (\%) \\
\hline Beach & Provisioned & 25 \\
Invasive acacia & Provisioned & 12 \\
& Non-provisioned & 64 \\
Mangrove & Provisioned & 5 \\
Restored savannah & Provisioned & 2 \\
& Non-provisioned & 24 \\
Savannah & Provisioned & 1 \\
Secondary forest & Non-provisioned & 3 \\
& Provisioned & 50 \\
Settlements & Non-provisioned & 9 \\
\hline
\end{tabular}

*the non-provisioned group in dry season employed the following habitats: savannah $(1 \%)$, restored savannah $(20 \%)$, invasive acacia $(72 \%)$, secondary forest ( $5 \%)$, beach $(0.5 \%)$, mangrove $(0.5 \%)$, settlements $(1 \%)$.

TABLE 4 Home range of the provisioned group according to visitor number using 90\% AKDE home range analysis

\begin{tabular}{lcccc}
\hline Group & No. of visitors* & Low (ha) & Mean (ha) & High (ha) \\
\hline Provisioned & $<100$ & 10.32 & 12.45 & 14.77 \\
Provisioned & $100-300$ & 10.49 & 12.03 & 13.68 \\
Provisioned & $301-500$ & 6.30 & 8.46 & 10.95 \\
Provisioned & $>500$ & 4.88 & 5.89 & 6.98 \\
\hline
\end{tabular}

*<100: weekdays in non-holiday season (October-November 2017, 14 days), 100-300: weekends in non-holiday season and weekdays in holiday season (December 2017 - January 2018, 27 days), 301-500: Weekends in holiday season (6 days), >500: holidays in holiday season (12 days). 


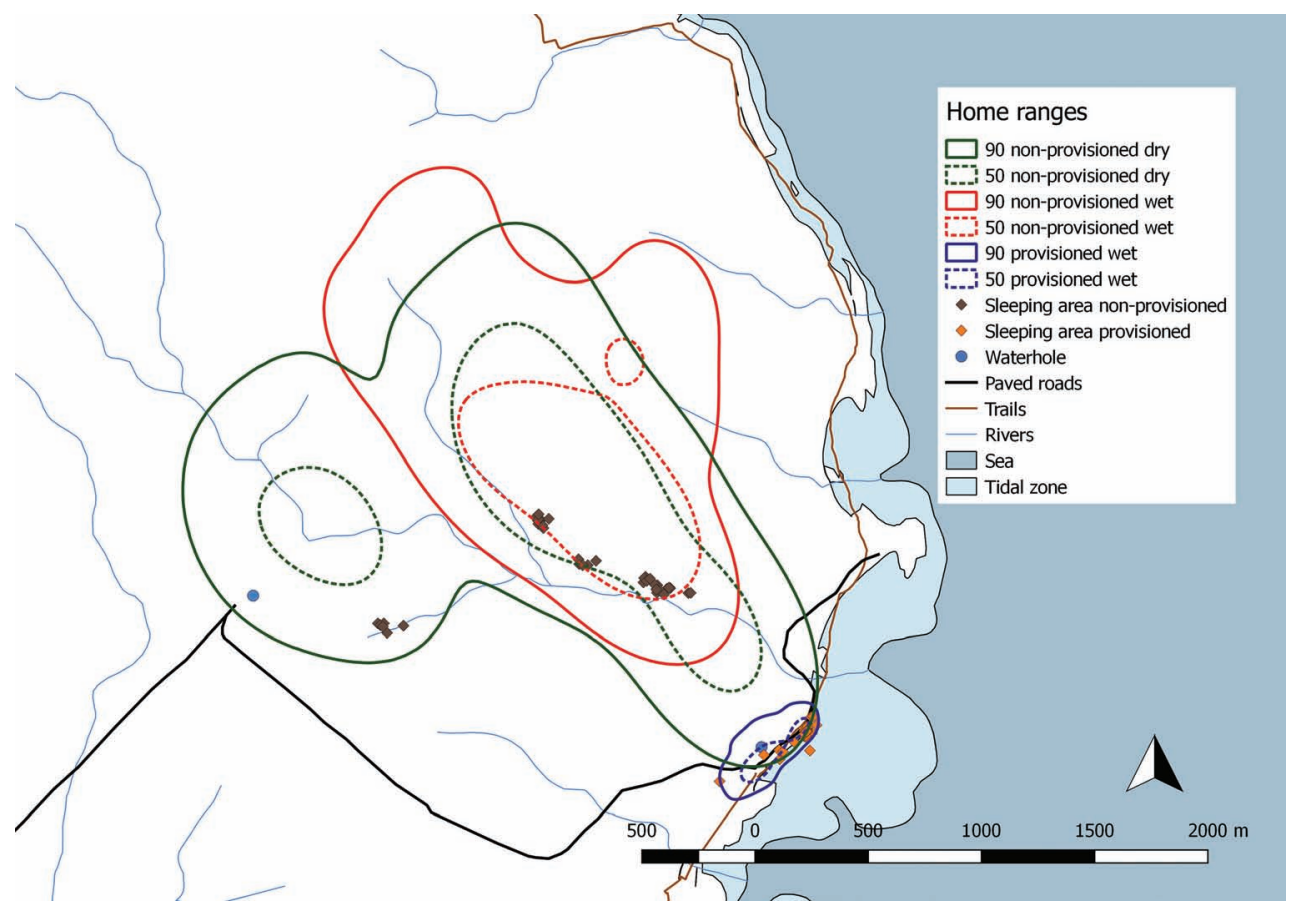

FIGURE 29 90\% AKDE home range and 50\% AKDE core area for the provisioned and non-provisioned group including sleeping areas in Baluran National Park.

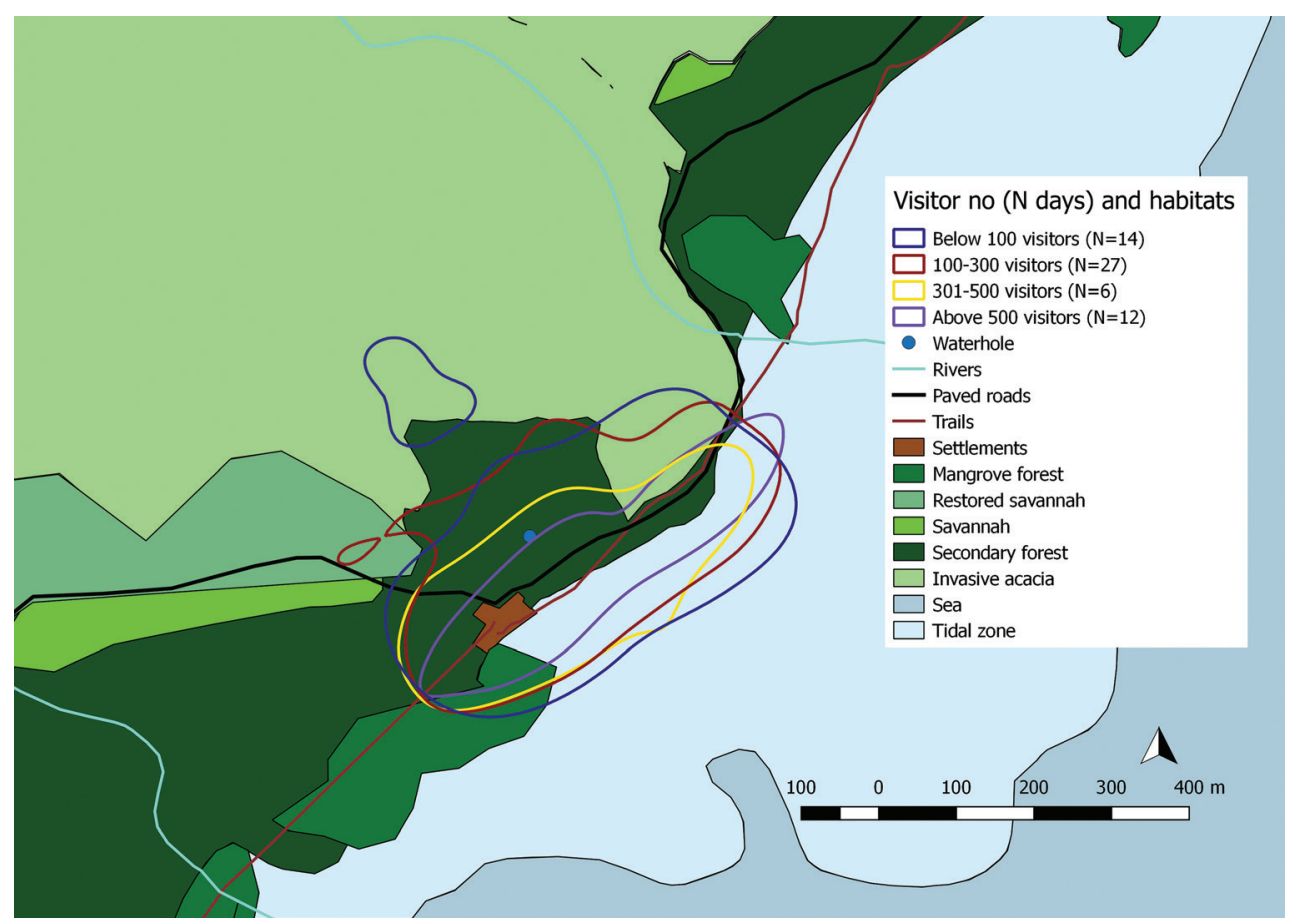

FIGURE 3 Home range according to visitor number for the provisioned group using 90\% AKDE home range analysis. 
The habitat selection of the provisioned group showed a preference for settlements, and an avoidance of invasive acacia and mangrove (table $5 \mathrm{~A}$ ). Beach was preferred during night over daytime (table $5 \mathrm{~A}$ ). In the same season, the non-provisioned group avoided invasive acacia and preferred secondary forest (table $5^{\mathrm{A}}$ ). In the dry season, the non-provisioned group still avoided invasive acacia yet now preferred secondary forest to the other habitats (table $5^{\mathrm{B}}$ ). There was no change in habitat selection between day and night for the non-provisioned group.

For the non-provisioned group in dry season we found a daily path length of $3569 \pm$ $812 \mathrm{~m}$, which was larger than wet season daily path length, yet not statistically significantly so. The dry season home range of the non-provisioned group included waterholes, which were not included in the wet season home range (fig. 2). The non-provisioned home range shifted to the north in the wet season (fig. 2). Non-provisioned group sleeping areas were mostly located in the overlap between the wet and dry season estimated mean $50 \%$ core areas, alongside rivers (fig. 2). The estimated mean 90\% dry season home range size of the non-provisioned group was approximately $\mathbf{1 . 5}$ time larger than the estimated mean wet season 90\% home range (table 2 ).

In the dry season, the non-provisioned group travelled significantly faster through

TABLE 5A Habitat selection by group in the wet season (preferred habitats in italics)

\begin{tabular}{llcccl}
\hline Group & Habitat & coef & se(coef $)$ & $\mathrm{z}$ & $\operatorname{Pr}(>|\mathrm{z}|)$ \\
\hline Provisioned & Beach* & 0.006 & 0.003 & 2.35 & $0.019^{* * * *}$ \\
& Invasive acacia & -0.011 & 0.003 & -3.58 & $0.00035^{* *}$ \\
& Mangrove & -0.014 & 0.005 & -3.17 & $0.0015^{* * *}$ \\
& Restored savannah & -0.008 & 0.006 & -1.32 & 0.188 \\
& Secondary forest & -0.003 & 0.002 & -1.77 & 0.0771 \\
& Settlements & 0.015 & 0.002 & 6.97 & $3.17 \mathrm{e}-12^{* *}$ \\
Non-provisioned & Invasive acacia & -0.0055 & 0.0019 & -2.895 & $0.00679^{* * *}$ \\
& Restored savannah & 0.0044 & 0.0021 & 2.101 & $0.035^{* * * *}$ \\
& Savannah & -0.0064 & 0.0054 & -1.177 & 0.239 \\
& Secondary forest & 0.0027 & 0.0030 & 0.903 & 0.367 \\
\hline
\end{tabular}

*the significance refers to night-time $(4 \mathrm{am}-7$ am and $5 \cdot 30-6.15 \mathrm{pm}) ;{ }^{* *} 0.001$ significant; ${ }^{* *} 0.01 ;{ }^{* * * *} 0.05$.

TABLE 5В Habitat selection by season for the non-provisioned group (preferred habitats in italics)

\begin{tabular}{llcccl}
\hline Season & Habitat & coef & se(coef) & $\mathbf{z}$ & $\operatorname{Pr}(>|\mathbf{z}|)$ \\
\hline \multirow{2}{*}{ Wet } & Invasive acacia & -0.0055 & 0.0019 & -2.895 & $0.00679^{* * *}$ \\
& Restored savannah & 0.0044 & 0.0021 & 2.101 & $0.0356^{* * *}$ \\
& Savannah & -0.0064 & 0.0054 & -1.177 & 0.239 \\
& Secondary forest & 0.0027 & 0.0030 & 0.903 & 0.367 \\
\multirow{3}{*}{ bry } & Invasive acacia & -0.0048 & 0.0019 & -2.587 & $0.00969^{* *}$ \\
& Restored savannah & 0.0015 & 0.0021 & 0.708 & 0.4790 \\
& Savannah & -0.1696 & 19.572 & -0.009 & 0.993 \\
& Secondary forest & 0.0098 & 0.0023 & 4.222 & $2.45 \mathrm{e}-05^{*}$ \\
\hline
\end{tabular}

*0.001 significant; ${ }^{* *} 0.01 ;{ }^{* * *} 0.05$. 
invasive acacia than through restored savannah $(W=48681, P<0.005)$ and secondary forest $(W=55396, P<0.005)$, but also significantly faster through restored savannah than through secondary forest $(W=14940, P<$ 0.005). In the wet season, there were no significant differences in speeds for the nonprovisioned group. For the provisioned group, the speed was significantly faster in invasive acacia compared to beach $(W=6100, P<$ 0.005), mangrove $(W=709, P<0.05)$, secondary forest $(W=16485, P<0.005)$, and settlements $(5495, P<0.005)$. The group moved significantly slower in settlements compared to beach $(W=29268, P<0.005)$, restored savannah $(W=1984, P<0.005)$, and secondary forest $(W=46426, P<0.005)$.

\section{Discussion}

Human presence in Baluran National Park appeared to affect movement, home range, core area and habitat preference of long-tailed macaques. Our analysis found a correlation between human presence and home range size in the provisioned group and not in the nonprovisioned group. However, many factors could have affected our results. The amount and type of habitats and thereby natural food availability differ slightly between the two groups. Differences in plant productivity and biomass between study group home ranges could have affected our results. In the nonprovisioned group, we found seasonality to affect home range size and area. Seasonality may also have affected the provisioned group; however, we were not able to collect data during dry season for the provisioned group because of GPS-collar malfunction and reduced battery life. Our direct observations of the provisioned group during a full year suggests that seasonality does not have the same impact on home range as visitor number does.
Our results showed the substantive plasticity in long-tailed macaque behavioural ecology. Studies on other wildlife species have documented similar results for provisioned wildlife species (i.e., Sorensen et al., 2014; Klegarth et al., 2017). However, it is the first time a group of wildlife devoid of human contact inhabiting similar habitats adjacent to the provisioned group has been included. While we did not observe a home range overlap during the GPS-collaring period of the provisioned group, the non-provisioned group ranged into the area of the provisioned group during the dry season. During our time observing the two groups after collaring had ended, we even observed an aggressive encounter between the two groups in the home range of the provisioned group, which lasted several days until the non-provisioned group was defeated. During this time, the non-provisioned group came close to visitors, and they did so every time they entered the home range of the provisioned group. This could have led to an anthropogenic effect on the non-provisioned group, yet it did not appear to, which may be due to historical relationships between the two groups and/or cultural differences within groups (Whiten, 2019).

One of our expectations prior to conducting this study was to find constricted space use by the provisioned group compared to the non-provisioned group, and indeed both DPL, home range and core area size were smaller for the provisioned group compared to the nonprovisioned group. The greater DPL by the non-provisioned group suggested that they had to travel further to forage and find water sources, an effect also reflected in the differences in DPL between seasons. Baluran National Park experienced a severe dry season, and a very wet season. These two seasons were different in all aspects, from water availability, to food availability, to substrate composition. With food items readily available in the same 
area through provisioning, the provisioned group did not need to travel as far as the nonprovisioned group. According to a botanist working in Baluran National Park, the home range of the provisioned group included more consumable plant species than the home range of the non-provisioned group. This could also have affected our results. The provisioned group might have had sufficient food in their home range even without provisioning by humans. However, increased visitor numbers significantly influenced the home range size of the provisioned group (table 4, fig. 3), which indicates that human presence, probably due to provisioning did affect the home range size of the provisioned group, and this should have implications for future management plans. Provisioning may also have other trophic effects when constricting home ranges of certain groups of one species in an ecosystem (Milner et al., 2014). For other species, aggregation at feeding sites may negatively affect the reproduction of sympatric species, and increase predation on particular species (Milazzo et al., 2006).

Increasing visitor number constricted home range (fig. 3). On holidays, especially Christmas and New Year's holiday with over $>500$ visitors per day, home ranges were reduced markedly to almost only include human influenced areas (fig. 3). Baluran National Park recently re-asphalted the tourist road leading to Bama beach (after data collection for this study), and tourist numbers have gone from maximum 1000 tourists/day, and only in the holiday season to several thousand every day. The effects of this on wildlife ranging patterns are unknown, yet our results show that even a minor change $( \pm 100-200$ visitors $)$ can have substantial impacts. The ecological consequences of this may be a neglect of ecological roles, such as seed dispersal. Rhesus macaques (Macaca mulatta) decreased their seed dispersal in provisioning periods (Sengupta et al., 2015). Furthermore, constricting home range to a very small area may increase depredation of long-tailed macaques on plants and animal species in that area, which could be unsustainable, as has been seen with provisioning of predatory fish (Milazzo et al., 2006) and Japanese macaques (Macaca mulatta) (Kurita, 2014).

The provisioned group preferred settlements, which is the Bama beach tourist area (table $5 \mathrm{~A}$ ). Beach was preferred at night-time, although not significantly, and many of the sleeping trees were located on the beach, or right next to the beach (fig. 2). The group significantly avoided invasive acacia and mangrove, although mangrove and mangrove species potentially could be a large part of the long-tailed macaque diet. Our limited study period could have affected our results, and it would be interesting to see if results are the same in a longitudinal study covering both seasons for one year or more. We only collected data from the provisioned group in the wet season. We found invasive acacia seeds to be a food source for long-tailed macaques, yet only during beginning and middle of dry season, when they were available, which may explain why invasive acacia was avoided in wet season.

Group sizes did not differ much in our study. However, group size may affect ranging patterns even without provisioning. A study in Sumatra found significantly larger day journey length with higher group size (van Schaik et al., 1983). Our DPL was significantly larger for the non-provisioned group. The density of the provisioned group was much larger than that of the non-provisioned group (table 2), with 838 ind $/ \mathrm{km}^{2}$ ( $\left.8.38 \mathrm{ind} / \mathrm{ha}\right)$ this lies within the range of provisioned groups in Bali $555^{-5850}$ ind/ $\mathrm{km}^{2}$ (Wheatley, 1989; Brotcorne, 2014). The high density of the provisioned group may increase the potential for pathogen transmission within the species, and between macaques and humans, as has been shown for macaque groups in other areas (Jones-Engel et al., 2001; 
Engel et al., 2002;). The non-provisioned group density was $17-25 \mathrm{ind} / \mathrm{km}^{2}$ (0.17-0.25 ind/ha) depending on season, which is lower than mean group density for Java of $55 \mathrm{ind} / \mathrm{km}^{2}$ (Fooden, 1995), and lower than the 7 oind $/ \mathrm{km}^{2}$ group density for a non-provisioned group in West Bali National Park (Brotcorne, 2014). This is also lower than the mean density for the entire national park ( 41 ind. $/ \mathrm{km}^{2}$ ) (Hansen et al., 2019).

Daily path length of the non-provisioned group was higher in dry season, which correlates well with the increase in home range size in dry season (table 2). Increases were however not significant. We suggest that presence of waterholes drove the increase in dry season (fig. 2). The dry season in Baluran National Park is severe, and many rivers dry out, leaving few waterholes with available drinking water. The non-provisioned group avoided areas with invasive acacia, both for wet and dry season. However, we also do not have data for this group from the period of invasive acacia seeds. Invasive acacia covered a large part of the home range of the non-provisioned group, and was mainly devoid of food sources, except small enclaves of fruiting trees. We also found that the non-provisioned group travelled faster through this habitat than other habitats. During wet season, restored savannah was preferred above the other habitats. Restored savannah plants and trees bloomed and fruited during wet season, and the habitat contained several different food sources. Secondary forest was also a preferred habitat during wet season, where trees were fruiting. During dry season, the restored savannah and native savannah dried out, and we saw a significant preference shift to secondary forest in dry season. Secondary forest contained both deciduous and evergreen plants, and therefore contained food sources year round. The group avoided savannah in both seasons; however, native savannah was a very small part of the home range of both groups.
Our results presented effects of human provisioning on wildlife, which can alter the behavioural ecology of a species, and shift main drivers for habitat preference and ranging patterns. For the non-provisioned group, seasonality and the related food and water availability seemed to be the main drivers of ranging patterns, yet for the provisioned group human presence seemed to determine food and water availability. This study only incorporated two groups, one provisioned and one non-provisioned group. This reduced our population inference and left us unable to conclude if our results for the two groups were representative of the Baluran National Park population. To investigate this we need to include more groups (provisioned and non-provisioned).

Our results indicated an effect of provisioning on long-tailed macaque home range size, and if effects of provisioning and human presence are to be reduced, we advise areas with long-tailed macaques to regulate provisioning. Baluran National Park and other sites in Java have a desire to cease provisioning through different measures, which should gradually reduce provisioning until a full stop (RM Wiwied Widodo, pers. comm.). Completely ceasing it abruptly though may cause conflicts between and within long-tailed macaque groups and it may increase aggression towards visitors in the park. Monitoring and researching the process of reducing provisioning, focusing on the behaviour of the macaques and the effects on sympatric plants and animals is crucial for our understanding and for future management. We recommend areas with human-long-tailed macaque interfaces to provide knowledge sharing programs on the effects of feeding on long-tailed macaques, and their ecosystems. Here we present home range size and habitat selection, yet other studies have provided information on the increase of human-directed aggression from long-tailed macaques (Fuentes et al., 
2007, 2008; Sha et al., 2009) and the risks of pathogen transmission (Jones-Engel et al., 2008). There are risks associated with humanmacaque interactions, and here we showed that the movement ecology of long-tailed macaques might also be affected, which could have severe consequences for the ecosystems they inhabit. We urge researchers to conduct studies on cascading trophic effects of longtailed macaque provisioning.

The ranging patterns of other macaque species may also be affected by provisioning, and as we see in table 1 . Our results can be used by researchers and managers of other macaque species to advise in provisioning matters, as many macaque species are synathropic to some extent as the long-tailed macaque. Macaques are opportunistic and behaviourally flexible (Thierry, 2007), which enables them to exploit human food sources and approach humans closely. However, as we see here this interaction may alter the ranging behaviour of the macaques, possibly changing their ecological role in the habitat they inhabit.

Other mammals have also shown to be affected by provisioning, and we urge practitioners in all areas where wildlife is provisioned to consider our results. If ranging patterns are affected by provisioning, the effects of this should be investigated. Provisioning of wildlife by humans may have severe consequences on not only the provisioned species, yet also the ecosystems they inhabit. Restricting home ranges may restrict seed dispersal and other important ecological roles. Provisioning of wildlife should be conducted with caution and knowledge of the consequences.

\section{Acknowledgements}

We are grateful to the Indonesian Ministry of Forestry and Environment - Department for Conservation of Natural Resources and
Ecosystems Dirjen Ir. Wiratno for their support, and the Indonesian Ministry of Research and Technology for granting research permission. We are also grateful to Kepala Balai Ir. Bambang Sukendro, all the Baluran National Park rangers for their support and advice. Ibu Arif Pratiwi has been an invaluable support and help during our time in Baluran National Park, and we cannot thank her enough. We would also like to thank the people of Wonorejo, especially Pak Kepala Desa Sumarto Adi for their support, and interest in this project and for always making us all feel at home. Thank you to Kathleen D. Reinhardt for revision and thank you to Innovation Fund Denmark (project no. 5189-00135B) for financial support. We have no conflicts of interests to declare.

\section{References}

Altmann, J. (1974) Observational study of behavior: Sampling methods. Behaviour, 49, 227-267. doi: 10.1080/14794802.2011.585831.

Avgar, T., Lele, S.R., Keim, J.L. \& Boyce, M.S. (2017) Relative Selection Strength: Quantifying effect size in habitat- and step-selection inference. Ecol. Evol., 7, 5322-5330. doi:10.1002/ece3.3122.

Brotcorne, F. (2014) Behavioural ecology and commensal long-tailed macaque (Macaca fascicularis) populations in Bali, Indonesia: impact of anthropic factors. Université de Liège (unpublished doctoral dissertation).

Brotcorne, F, Giraud, G., Gunst, N., Fuentes, A., Wandia, I.N., Beudels-Jamar, R.C., Poncin, P., Huynen, M.C. \& Leca, J.B. (2017) Intergroup variation in robbing and bartering by longtailed macaques at Uluwatu Temple (Bali, Indonesia). Primates, 58, 505-516. doi:10.1007/ s10329-017-0611-1.

Brotcorne, F., Maslarov, C., Wandia, I.N., Fuentes, A., Beudels-Jamar, R.C. \& Huynen, M.C. (2014) The role of anthropic, ecological, and social factors in sleeping site choice by long-tailed Down ldadeg from Brill. comఠ4/26/2823 12:54:52PM 
Macaques (Macaca fascicularis). Am. J. Primatol., 76, 1140-1150. doi:10.1002/ajp.22299.

Brotcorne, F., Wandia, I.N., Rompis, A., Soma, I.G., Suartha, I.N. \& Hunyen, M.C. (2011) Recent demographic and behavioural data of Macaca fascicularis at Padangtegal, Bali, Indonesia. In: M.D. Gumert, A. Fuentes \& L. Jones-Engel (Eds) Monkeys on the Edge. Ecology and Management of Long-Tailed Macaques and their Interface with Humans, pp. 180-182. Cambridge University Press, Cambridge.

Calenge, C. (2011) Analysis of Animal Movements in R: the adehabitatLT Package, 1-86.

Chatterjee, M., Mukhopadhyay, K. \& Sinha, A. (2009) A many-splendored world! Long-term studies on bonnet macaques in the Bandipur National Park - Mudumalai Wildlife Sanctuary, southern India. In: Eighth Göttinger Freilandtage: Long-term Field Studies of Primates. German Primate Centre, Göttingen.

Chhangani, A.K. (2004) Killing of Hanuman langur (Semnopithecus entellus) in road accidents in Kumbhalgarh wildlife sanctuary, Rajasthan, India. Primate Rep., 69, 49-57.

Cooper, S.M., Owens, M.K., Cooper, R.M. \& Ginnett, T.F. (2006) Effect of supplemental feeding on spatial distribution and browse utilization by white-tailed deer in semi-arid rangeland. J. Arid Environ., 66, 716-726. doi:10.1016/j .jaridenv.2005.11.015.

Dore, K.M, Hansen, M.F., Klegarth, A.R., Fichtel, C., Koch, F., Springer, A., Kappeler, P., Parga, J.A., Humle, T., Colin, C., Raballand, E., Huang, Z-P., Qi, X-G., Di Fiore, A., Link, A., Stevenson. P.R., Stark, D.J., Tan, N., Gallagher, C.A., Anderson, C.J., Campbell, C. J., Kenyon, M., Pebsworth, P., Sprague, D., Jones-Engel, L., \& Fuentes, A. (2020) Review of GPS collar deployments and performance on nonhuman primates. Primates. doi:10.1007/s10329-020-00793-7.

EB. (2018). Encyclopaedia Britannica, Java. https:// www.britannica.com/place/Java-islandIndonesia.

Engel, G.A., Jones-Engel, L., Schillaci, M.A., Suaryana, K.G., Putra, A., Fuentes, A. \& Henkel, R.
(2002) Human exposure to herpesvirus Bseropositive macaques, Bali, Indonesia. Emerg. Infect. Dis., 8, 789-795.

Fernando, P., Polet, G., Foead, N., Ng, L.S., Pastorini, J. \& Melnick, D.J. (2006) Genetic diversity, phylogeny and conservation of the Javan rhinoceros (Rhinoceros sondaicus). Conserv. Genet., 7, 439-448. doi:10.1007/s10592-0o6-9139-4.

Fleming, C.H. \& Calabrese, J.M. (2017) A new kernel density estimator for accurate home-range and species-range area estimation. Methods Ecol. Evol., 8, 571-579. doi: 10.1111/2041-210X .12673 .

Fleming, C.H., Calabrese, J.M., Dong, X., Winner, K., Péron, G., Noonan, M.J., Kranstauber, B., Gurarie, E., Safi, K., Cross, P.C., Mueller, T., de Paula, R.C., Akre, T., Drescher-Lehman, J., Harrison, A-L. \& Morato, R.G. (2019) Continuous-Time Movement Modelling.CRAN.

Fooden, J. (1995) Systematic Review of Southeast Asian Longtail Macaques, Macaca fascicularis (Raffles, (1821)), Fieldiana Zoology new series, no. 81. Field Museum of Natural History, Chicago, IL.

Fuentes, A., Kalchik, S., Gettler, L., Kwiatt, A., Konecki, M. \& Jones-Engel, L. (2008) Characterizing human-macaque interactions in Singapore. Am. J. Primatol., 70, 879-883. doi:10.1002/ ajp.20575.

Fuentes, A., Rompis, A., Putra, I.G.A.A., Watiniasih, N.L., Suartha, I.N., Soma, I.G., Wandia, I.N., Putra, I.D.K.H., Stephenson, R. \& Selamet, W. (2011) Macaque behaviour at the human-monkey interface: The activity and demography of semi-freeranging Macaca Fascicularis at Padangtegal, Bali, Indonesia. In: M.D. Gumert, A. Fuentes \& L. Jones-Engel (Eds), Monkeys on the Edge. Ecology and Management of Long-Tailed Macaques and their Interface with Humans, pp. 159-182. Cambridge University Press, Cambridge.

Fuentes, A., Shaw, E. \& Cortes, J. (2007) Qualitative assessment of macaque tourist sites in Padangtegal, Bali, Indonesia, and the upper rock nature reserve, Gibraltar. Int. J. Primatol., 28, 11431158. doi:10.1007/s10764-007-9184-y. 
Gumert, M.D., Fuentes, A. \& Jones-Engel, L. (2011) Monkeys on the Edge: Ecology and Management of Long-Tailed Macaques and their Interface with Humans. Cambridge University Press, Cambridge.

Hansen, M.F., Nawangsari, V.A., van Beest, F.M., Schmidt, N.M., Traeholt, C., Fuentes, A., Stelvig, M. \& Dabelsteen, T. (2019) Estimating densities and spatial distribution of a commensal primate species, the long-tailed macaque (Macaca fascicularis). Conservation Science and Practice. doi:10.1111/csp2.88.

Hansen, M.F., Wahyudi, H.A., Supriyanto, S. \& Damanik, A.R. (2015) The interactions between long-tailed macaques (Macaca fascicularis) and tourists in Baluran National Park, Indonesia. Journal of Indonesian Natural History, 3, 36-41.

Izumiyama, S., Mochizuki, T. \& Shiraishi, T. (2003) Troop size, home range area and seasonal range use of the Japanese macaque in the Northern Japan Alps. Ecol. Res., 18, 465-474.

Jackson, P. \& Nowell, K. (2008) Panthera tigris ssp. sondaica. The IUCN Red List of Threatened Species 2008: e.T41681A10509194. doi:10.2305/IUCN. UK.2008.RLTS.T41681A10509194.en.

Jones-Engel, L., Engel, G.A., Schillaci, M.A., Babo, R. \& Froehlich, J. (2001) Detection of antibodies to selected human pathogens among wild and pet macaques (Macaca tonkeana) in Sulawesi, Indonesia. Am. J. Primatol., 54, 171-178.

Jones-Engel, L., May, C.C., Engel, G.A., Steinkraus, K.A., Schillaci, M.A., Fuentes, A., Rompis, A., Chalise, M.K., Aggimarangsee, N., Feeroz, M.M., Grant, R., Allan, J. S., Putra, A., Wandia, I. N., Watanabe, R., Kuller, L., Thongsawat, S., Chaiwarith, R., Kyes, R.C. \& Linial, M.L. (2008) Diverse contexts of zoonotic transmission of simian foamy viruses in Asia. Emerg. Infec. Dis., 14, 1200-1208. doi:10.3201/eid1408.071430.

José-Domínguez, J.M., Huynen, M., García, C.J., Albert-Daviaud, A., Savini, T. \& Asensio, N. (2015) Non-territorial macaques can range like tTerritorial gibbons when partially provisioned with food. Biotropica, 47, 733-744.
Klegarth, A.R. (2017). Measuring movement: How remote telemetry facilitates our understanding of the human-macaque interface. In: K.M. Dore, E.P. Riley \& A. Fuentes (Eds) Ethnoprimatology. A Practical Guide to Research at the HumanNonhuman Primate Interface, pp. 70-87. Cambridge University Press, Cambridge.

Klegarth, A.R., Hollocher, H., Jones-Engel, L., Shaw, E., Lee, B.P.Y.H., Feeney, T., Holmes, D., Laguea, D. \& Fuentes, A. (2017) Urban primate ranging patterns: GPS-collar deployments for Macaca fascicularis and M. Sylvanus. Am.J. Primatol., 79, 1-17. doi:10.1002/ajp.22633.

Kubasiewicz, L.M., Bunnefeld, N., Tulloch, A.I.T., Quine, C.P. \& Park, K.J. (2016) Diversionary feeding: an effective management strategy for conservation conflict? Biodivers. Conserv., 25, 122. doi:10.1007/s10531-015-1026-1.

Milazzo, M., Anastasi, I. \& Willis, T.J. (2006) Recreational fish feeding affects coastal fish behaviour and increases frequency of predation on damselfish Chromis chromis nests. Mar. Ecol. Prog., 310, 165-172. doi:10.3354/meps310165.

Milner, J.M., Van Beest, F.M., Schmidt, K.T., Brook, R.K. \& Storaas, T. (2014) To feed or not to feed? Evidence of the intended and unintended effects of feeding wild ungulates. J. Wildlife Manage., 78, 1322-1334. doi:10.1002/jwmg.798.

Muroyama, Y. \& Eudey, A.A. (2004) Do macaque species have a future? In: B. Thierry, M. Singh, \& W. Kaumanns (Eds) Macaque Societies: A Model for the Study of Social Organization, pp. 328-332. Cambridge University Press, Cambridge.

Ong, P. \& Richardson, M. (2008) Macaca fascicularis ssp. fascicularis. The IUCN Red List of Threatened Species 2008: e.T39768A10255883.

Pudyatmoko, S. (2017) Free-ranging livestock influence species richness, occupancy, and daily behaviour of wild mammalian species in Baluran National Park, Indonesia. Mamm. Biol., 86, 3341. doi:10.1016/j.mambio.2017.04.001.

Pudyatmoko, S., Budiman, A. \& Kristiansen, S. (2018) Towards sustainable coexistence: People and wild mammals in Baluran National Park, 
Indonesia. Forest Policy Econ., 90, 151-159. doi:10.1016/j.forpol.2018.02.006.

R Core Team. (2017) R: A Language and Environment for Statistical Computing. Vienna: R Foundation for Statistical Computing.

Reynolds, S.J., Galbraith, J.A., Smith, J.A. \& Jones, D.N. (2017) Garden bird feeding: Insights and prospects from a North-South cComparison of this global urban phenomenon. Front. Ecol. Evol., 5, 24. doi:10.3389/fevo.2017.00024.

Richard, A.F., Goldstein, S.J.,\& Dewar, R.E. (1989) Weed macaques: The evolutionary implications of macaque feeding ecology. Int. J. Primatol., 10, 569-594. doi:10.1007/BF02739365.

Riley, E.P. (2005) The loud call of the Sulawesi Tonkean macaque, Macaca tonkeana. Tropical Biodiversity, 8, 199-209.

Samuels, A. \& Bejder, L. (2004) Chronic interaction between humans and free-ranging bottlenose dolphins near Panama City Beach, Florida, USA.J. Cetacean Res. Manag., 6, 69-77.

Sengupta, A., McConkey, K.R. \& Radhakrishna, S. (2015) Primates, provisioning and plants: Impacts of human cultural behaviours on primate ecological functions. PLOS ONE, 10, 1-13. doi:10.1371/journal.pone.0140961.

Sha, J.C.M., Gumert, M.D., Lee, B.P.Y.H., JonesEngel, L., Chan, S. \& Fuentes, A. (2009) MacaqueHuman interactions and the societal perceptions of macaques in Singapore. Am.J. Primatol., 71, 825-839. doi:10.1002/ajp.20710.

Sha, J.C.M. \& Hanya, G. (2013) Diet, activity, habitat use, and ranging of two neighbouring groups of food-enhanced long-tailed macaques (Macaca fascicularis). Am. J. Primatol., 75, 581-592. doi:10.1002/ajp.22137.

Signer, J., Fieberg, J. \& Avgar, T. (2019a) Animal movement tools (amt): $\mathrm{R}$ package for managing tracking data and conducting habitat selection analyses. Ecol. Evol., 9, 880-89o. doi:10.1002/ ece3.4823.

Signer, J., Reineking, B., Schlaegel, U., \& LaPoint, S. (2019b) Animal Movement Tools. CRAN.

Sikes, R.S. \& the Animal Care and Use Committee of the American Society of Mammalogists (2016)
2016 Guidelines of the American Society of Mammalogists for the use of wild mammals in research and education. J. Mammal., 97, 663688. doi:10.1093/jmammal/gywo78.

Sinha, A. \& Mukhopadhyay, K. (2013) The monkey in the town's commons, revisited: An anthropogenic history of the Indian Bonnet Macaque. In: S. Radhakrishna, M. Huffman, A. Sinha (Eds) The Macaque Connection. Developments in Primatology: Progress and Prospects, pp. 187-208. Springer, New York.

Sorensen, A., van Beest, F.M. \& Brook, R.K. (2014) Impacts of wildlife baiting and supplemental feeding on infectious disease transmission risk: A synthesis of knowledge. Prev. Vet. Med., 113, 356-363. doi:10.1016/j.prevetmed.2013.11.o10.

Thierry, B. (2007) The macaques. A double-layered social organization. In: C.J. Campbell, A. Fuentes, K.C. MacKinnon, M. Panger \& S.K. Bearder (Eds) Primates in Perspectives, pp. 224-239. Oxford University Press, Oxford.

van Schaik, C.P. \& van Noordwijk, M.A. (1988) Scramble and contest in feeding competition among female long-tailed macaques (Macaca fascicularis). Behaviour, 105, 77-98.

van Schaik, C.P., van Noordwijk, M.A., Boer, R.J. \& den Tonkelaar, I. (1983) The effect of group size on time budgets and social behaviour in wild long-tailed macaques (Macaca fascicularis). Behav. Ecol. Sociobiol., 13, 173-181.

Wheatley, B.P. (1989) Diet of Balinese temple monkeys Macaca fascicularis. Kyoto University Overseas Research Report of Studies on Asian NonHuman Primates, 7, 62-75.

Whiten, A. (2019) Cultural evolution in animals. Annu. Rev. Ecol., Evol. S., 50, 1-22. doi:10.1146/ annurev-ecolsys-110218-025040.

Yeo, J.H. \& Neo, H. (2010) Monkey business: humananimal conflicts in urban Singapore. Soc. Cult. Geogr., 11, 681-699.

RECEIVED: 10 JANUARY 2020 | REVISED AND ACCEPTED: 31 APRIL 2020

EDITOR: V. NIJMAN 